\title{
DESENVOLVIMENTO DE MUDAS DE CEDRO-ROSA EM SOLO CONTAMINADO COM COBRE: TOLERÂNCIA E POTENCIAL PARA FINS DE FITOESTABILIZAÇÃO DO SOLO ${ }^{1}$
}

\author{
Sandro Marcelo de Caires², Maurício Paulo Ferreira Fontes ${ }^{3}$, Raphael Bragança Alves Fernandes ${ }^{3}$, Júlio \\ César Lima Neves ${ }^{3}$ e Renildes Lúcio Ferreira Fontes ${ }^{3}$
}

\begin{abstract}
RESUMO - A contaminação do solo é frequentemente associada às atividades agrícolas, industriais e de mineração, bem como à reutilização de resíduos urbanos e, ou, de origem animal. Tais atividades podem promover o acúmulo de metais pesados no solo, elementos potencialmente nocivos à qualidade ambiental e ao bem-estar dos seres vivos. A fitorremediação é uma tecnologia de recuperação de áreas degradadas que visa à descontaminação do solo. Pela sua maior produção de biomassa, as espécies florestais são capazes de imobilizar e exportar para fora de qualquer sistema, através de sua biomassa, maiores quantidades de elementos químicos presentes no solo. Nesse contexto, este trabalho objetivou avaliar o desenvolvimento do cedro-rosa em solo contaminado com metais pesados. Mudas dessa árvore foram cultivadas em casa de vegetação, em solo contaminado com $\mathrm{Cu}\left(0,60,80,100,500 \mathrm{mg} \mathrm{kg}^{-1}\right)$, e, ao final de 105 dias, características das plantas e do solo foram analisadas. O cedro-rosa apresentou ganho de matéria seca até a dose de $100 \mathrm{mg} \mathrm{kg}^{-1} \mathrm{de} \mathrm{Cu}$, seguido de decréscimo no desenvolvimento vegetal nas doses maiores. Foi verificada maior partição de matéria seca para a raiz em detrimento da parte aérea. Os teores de $\mathrm{Cu}$ na planta responderam positivamente às doses aplicadas no solo. O fator de bioconcentração da raiz obtido sugere que o cedro-rosa possui acúmulo de Cu na raiz, o que permite indicar tal espécie como promissora para fins de fitoestabilização de solos contaminados.
\end{abstract}

Palavras-chave: Fitorremediação, Metais pesados, Recuperação de áreas degradadas e Cedrela fissilis Vell. (Meliaceae).

\section{DEVELOPMENT OF CEDRO-ROSA SEEDLINGS IN SOIL CONTAMINATED BY COPPER: TOLERANCE AND THE POTENTIAL FOR SOIL PHYTOSTABILIZATION PROPOSAL}

\begin{abstract}
Agricultural, industrial and mining activities are the mainly factors related to soil contamination, as well the reuse of urban and/or animal residues. These activities can produce heavy metals accumulation in soils, which are potentially dangerous chemical elements to environmental quality and to well-being of living beings. Phytoremediation is a technology for rehabilitation of degraded areas which aims the soil decontamination. Forest species can immobilize and export to outside of the system larger amounts of chemical elements from contaminated soil, because they have high biomass production. The objective of this study was to evaluate the Cedrela fissilis development in contaminated soil by heavy metals. With this propose, seedlings were cultivated in greenhouse and in a contaminated soil by $\mathrm{Cu}\left(0,60,80,100,500 \mathrm{mg} \mathrm{kg}^{-1}\right)$ for 105 days. After this period some soil and plant parameters were evaluated. Seedlings of C. fissilis presented crescent increments of dry matter until $100 \mathrm{mg} \mathrm{kg}^{-1}$ of $\mathrm{Cu}$, with reduction of vegetal development in the high doses. In general, it was verified high partition of dry matter to root system than aerial part. Plant Cu contents were correlated with applied doses in the soil. The root bioconcentraction factor of $C$. fissilis indicates potential capacity of this tree specie to phytostabilization works in contaminated soils.
\end{abstract}

Keywords: Phytoremediation, heavy metals, rehabilitation of degraded areas and Cedrela fissilis Vell. (Meliaceae)

\footnotetext{
${ }^{1}$ Recebido em 09.10.2009 e aceito para publicação em 31.10.2011.

${ }^{2}$ Instituto Federal do Norte de Minas Gerais, IFNMG, Campus Araçuaí, Brasil. E-mail: <sandrodecaires@yahoo.com.br>.

${ }_{3}^{3}$ Departamento de Solos, Universidade Federal de Viçosa, UFV, Brasil. E-mail: <mpfontes@ufv.br>, <raphael@ufv.br>,

<julio_n2003@yahoo.com.br>e <renildes@ufv.br>.
} 


\section{INTRODUÇÃO}

Os metais pesados são componentes naturais dos solos, uma vez que fazem parte da estrutura cristalina dos minerais que compõem as rochas, principal material de origem dos solos (ALLOWAY, 1993). A transferência de metais pesados no sistema solo-planta é um processo natural componente da ciclagem biogeoquímica de elementos químicos da natureza. Esse é um processo complexo governado por vários fatores naturais ou afetado pelo homem (KABATA-PENDIAS, 2004). Porém, tem sido cada vez mais frequente a constatação de contaminação do solo por metais pesados oriundos de atividades antrópicas, e essas áreas afetadas devem ser, por imposição legal, recuperadas.

A revegetação de solos e, ou, substratos contaminados com metais pesados diminui a dispersão dos contaminantes (VANGRONSVELD et al., 1995) e atua como agente de descontaminação ambiental (DENNY;WILKINS, 1987). Os vegetais permitem a recomposição da paisagem e, por meio da evapotranspiração, reduzem a saturação de água do solo, além de minimizar a erosão e a lixiviação dos metais pesados, protegendo mais as águas superficiais e subsuperficiais.

O uso da revegetação de locais contaminados, com o objetivo de minimizar os efeitos advindos da contaminação, é uma tecnologia conhecida como fitorremediação (SALT et al., 1998; LOMBI et al., 2001). A fitorremediação é considerada uma técnica emergente e de baixo custo para a "limpeza" de áreas contaminadas por metais pesados (ACCIOLY; SIQUEIRA, 2000; MELO et al., 2009). No entanto, ainda é restrita a relação de espécies de árvores nativas tropicais que reconhecidamente sejam efetivas para servir a esse propósito.

As espécies arbóreas nativas tropicais, principalmente as de rápido crescimento, apresentam características desejáveis para a fitorremediação de solos contaminados com metais pesados (fácil implantação, maior ciclo de vida e grande produção de biomassa), quando comparadas às plantas de ciclo curto. Tais peculiaridades permitem minimizar os custos de cultivo da área contaminada e a maior produção de biomassa, acumular maior quantidade de carbono e de metais pesados, o que é interessante nesses projetos de recuperação ambiental. Dessa forma, projetos de fitorremediação de solos contaminados com metais pesados utilizando espécies arbóreas nativas tropicais apresentam, ainda, potencial de sequestro de carbono, contribuindo com a diminuição do efeito-estufa (CAIRES et al., 2005).

As árvores podem ainda melhorar a qualidade do solo pela (i) capacidade de, juntamente com alguns microrganismos do solo, fixar $\mathrm{N}_{2}$ atmosférico durante o crescimento; (ii) por alterar a qualidade e quantidade da matéria orgânica do solo e transformar importantes propriedades, como densidade do solo, porosidade, capacidade de troca catiônica, potencial redox e condutividade hidráulica; (iii) por explorar, via sistema radicular, maior volume de solo, potencializando a extração de elementos químicos; e (iv) por alterar as condições microclimáticas do solo pela redução dos extremos de temperatura, aumentando a umidade e a aeração (FISHER, 1995). No caso de solos contaminados, Pulford e Watson (2003) salientaram ainda que a maior produção de litter das arbóreas promove rápida cobertura e proteção do solo, contribuindo para a formação de manta orgânica protetora da superfície.

As árvores, para serem utilizadas em fitorremediação, devem apresentar tolerância ao contaminante, sendo já bem conhecidos os possíveis mecanismos de tolerância aos metais pesados (TURNER, 1969; WOOLHOUSE, 1983; BAKER, 1987; LARCHER, 2004). Os metais pesados absorvidos por espécies arbóreas ficam mais tempo imobilizados nos tecidos vegetais, retardando seu retorno ao solo. Embora esse potencial seja conhecido, poucos são os estudos sobre a tolerância de espécies arbóreas tropicais em solos contaminados com esses elementos (PAIVA et al., 2002, 2003).

O cedro-rosa (Cedrela fissilis Vell. (Meliaceae)) é uma espécie arbórea nativa do Brasil e pode atingir até 40 m de altura e 200 cm de diâmetro, sendo considerada como secundária inicial ou secundária tardia. De acordo com Sakuragui et al. (2010), a espécie é naturalmente encontrada nos domínios fitogeográficos da Amazônia, Cerrado e Mata Atlântica. Ocorre tanto na floresta primária, principalmente nas bordas da mata ou clareiras, quanto em floresta secundária, sendo indicada em procedimentos de revegetação de áreas degradadas. Alguns estudos já avaliaram essa espécie em condições de exposição a metais pesados. Paiva et al. (2002a), estudando em solução nutritiva o efeito da aplicação de $\mathrm{Ni}$ sobre o teor de nutrientes na raiz, caule e folhas de mudas de cedro, concluíram que a aplicação do metal pesado aumentou o teor de $\mathrm{P}$, praticamente não afetou os teores de $\mathrm{K}$ e $\mathrm{S}$ e reduziu os de Ca e Mg nos tecidos 
vegetais. O teor de $\mathrm{Ni}$ na matéria seca de raiz, caule e folha elevou-se com o aumento das doses desse metal pesado. Em outro estudo, esses mesmos autores avaliaram os efeitos da toxidez de $\mathrm{Cd}$, Ni e $\mathrm{Pb}$ em mudas de cedro em solução nutritiva, constatando que o aumento das doses desses metais pesados exerceu efeitos sobre os índices de translocação de P, K, Ca, Mg, S, Cu, Fe, Mn e Zn, ora positivos, ora negativos, variando conforme o metal pesado e o nutriente (PAIVA et al., 2002b).

Marques et al. (2000) avaliaram mudas de cedrorosa cultivadas em solo argiloso misturado em diferentes proporções com substratos contaminados com metais pesados, concluindo que a espécie não foi afetada pela contaminação com esses metais. Entretanto, não foram encontrados na literatura trabalhos que avaliassem o desenvolvimento dessa espécie em solos de textura média ou arenosos contaminados e sem a aplicação de qualquer tipo de amenizantes ou condicionador.

Diante do exposto, o objetivo deste trabalho foi avaliar o desenvolvimento de mudas de cedro-rosa (Cedrela fissilis Vell. (Meliaceae)) em solo de textura média contaminado com $\mathrm{Cu}$, buscando avaliar o potencial de uso da espécie em programas de fitorremediação de solos contaminados com metais pesados.

\section{MATERIAL E MÉTODOS}

Para a avaliação do potencial do cedro-rosa na fitorremediação de solos contaminados com Cu, utilizou-se um Latossolo Amarelo Distrófico textura média (LAd) para a aplicação dos tratamentos. A seleção desse solo deveu-se à sua textura menos argilosa, o que implica menor poder adsortivo do metal pesado, buscando, dessa forma, submeter a espécie arbórea a maiores teores disponíveis do elemento.

O solo foi previamente seco à sombra e peneirado em malha de $4 \mathrm{~mm}$. Subamostras menores que $2 \mathrm{~mm}$ foram encaminhadas para análises químicas (Tabela 1) e físicas (Tabela 2) de caracterização nos laboratórios do Departamento de Solos da Universidade Federal de Viçosa (UFV), em Viçosa, MG.

As unidades experimentais foram formadas por 4,2 kg de amostra do LAd e dispostas em vasos plásticos que, previamente à aplicação dos tratamentos, receberam adubação NPK (200, 300, 200 mg kg-1 , respectivamente) a partir da aplicação de nitrato de amônio $\left(\mathrm{NH}_{4} \mathrm{NO}_{3}\right)$, fosfato de cálcio monocálcico $\left(\mathrm{Ca}\left(\mathrm{H}_{2} \mathrm{PO}_{4}\right)_{2} \cdot \mathrm{H}_{2} \mathrm{O}\right)$ e sulfato de
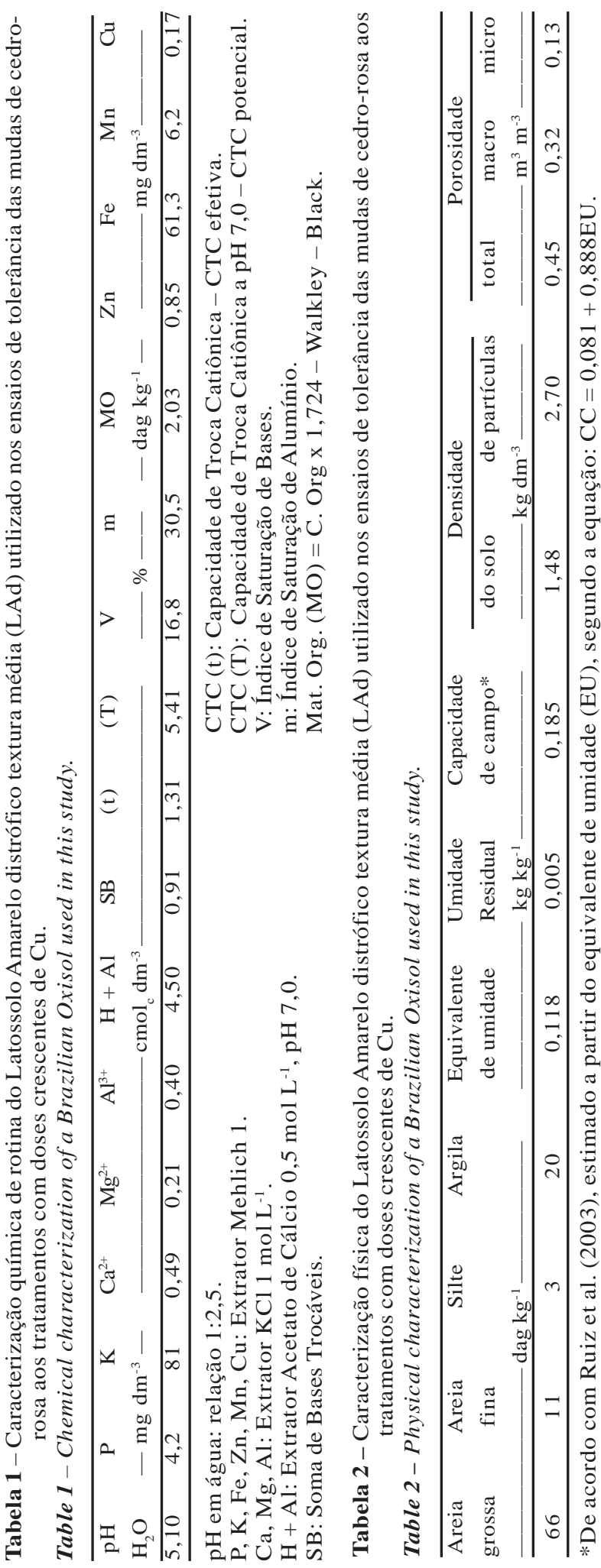
potássio $\left(\mathrm{K}_{2} \mathrm{SO}_{4}\right)$. Os tratamentos consistiram na aplicação de cinco doses de $\mathrm{Cu}\left(0,60,80,100,500 \mathrm{mg} \mathrm{kg}^{-1}\right)$, aplicadas na forma de nitrato de cobre $\left(\mathrm{Cu}\left(\mathrm{NO}_{3}\right)_{2} \cdot 3 \mathrm{H}_{2} \mathrm{O}\right)$. Na seleção das doses aplicadas, utilizaram-se como critério os valores orientadores de alerta $\left(60 \mathrm{mg} \mathrm{kg}^{-1}\right)$ e intervenção (500 $\mathrm{mg} \mathrm{kg}^{-1}$ ) do Cu em solos agrícolas, segundo recomendações da CETESB (2001). O valor de alerta utilizado no momento do experimento correspondeu ao valor de prevenção atualmente considerado para fins legais (CONAMA, 2009). Doses intermediárias entre esses dois valores foram empregadas para a definição dos demais tratamentos.

As mudas de cedro-rosa foram produzidas no viveiro florestal do Departamento de Engenharia Florestal da UFV e, no início do experimento, estavam com 6 meses de idade, possuíam diâmetro médio de 1,42 \pm 0,5 cm e uma altura média de 28,6 $\pm 2,4 \mathrm{~cm}$. Os substratos originais das mudas foram retirados, com o desnudamento das raízes sendo realizado como descrito por Marques et al. (2000) e Soares et al. (2001). Uma muda com raiz nua foi introduzida em cada vaso previamente selado com saco plástico, formando um sistema fechado para evitar perdas por drenagem. O conjunto + substrato + planta foi pesado e registrado individualmente. Na sequência foi adicionado a cada vaso um volume de água representando $70 \%$ da capacidade de campo (Tabela 2). Essa umidade foi mantida aproximadamente constante ao longo da duração do experimento por meio de pesagens de cada unidade experimental, de forma a repor as perdas por evapotranspiração.

O experimento foi conduzido considerando um delineamento em blocos casualizados, com quatro repetições. As mudas foram cultivadas por um período de 105 dias, entre os meses de julho e outubro, período após o qual amostras de solo foram tomadas e as plantas, colhidas, separando-se raiz e parte aérea. As amostras das partes vegetais foram secas em estufas com circulação de ar a $65^{\circ} \mathrm{C}$ até peso constante, para a obtenção da produção de matéria seca.

Subamostras do material vegetal triturado em moinho tipo Willey foram submetidas à digestão nítrico-perclórica, para fins de quantificação dos teores totais de Cu. A disponibilidade de Cu no solo foi avaliada nas amostras coletadas após o cultivo, a partir do uso do extrator DTPA, a pH 7,3 (ABREU et al., 2001). A quantificação dos teores de $\mathrm{Cu}$ nos tecidos vegetais e no solo foi efetuada por espectrofotometria de absorção atômica.
Os resultados de produção de matéria seca da raiz (MSR) e da parte aérea (MSPA) e da matéria seca total (MST), partição de matéria seca entre raiz (PRAIZ) e parte aérea (PPA), teor de Cu na raiz (TRAIZ) e na parte aérea (TPA), conteúdo de Cu na raiz (CRAIZ) e na parte aérea (CPA), partição de conteúdo de $\mathrm{Cu}$ entre a raiz (PCR) e a parte aérea (PCPA) e a disponibilidade de Cu no solo (DTPA) em função das doses aplicadas foram submetidos à análise de variância $(p<0,01)$. Nos casos em que se verificaram diferenças significativas dos efeitos dos tratamentos, os dados foram submetidos à análise de polinômios ortogonais, ajustando-se equações de regressão entre as doses aplicadas no solo e as variáveis supracitadas (STORCK et al., 2000). Todas as análises estatísticas foram efetuadas com o programa estatístico SAEG (RIBEIRO JÚNIOR, 2001). Com o objetivo específico de avaliar o potencial de descontaminação do solo pelo cedro-rosa, utilizou-se também o fator de bioconcentração (FBC) (VERVAEKE et al., 2003; ROSSELLI et al., 2003), que estima a quantidade do elemento acumulado na espécie em função de sua concentração no solo.

\section{RESULTADOS}

O impacto da retirada do substrato original das mudas e sua introdução nos vasos contendo os tratamentos foi evidente nos primeiros 10 dias, sendo verificado um processo gradativo de clorose seguido de queda foliar. Com 20 dias de cultivo, entretanto, todas as plantas já apresentavam gemas de brotação em desenvolvimento, indicando a superação dessa fase inicial. A partir desse momento, nos tratamentos com as duas maiores doses (100 e $500 \mathrm{mg} \mathrm{kg}^{-1}$ ) começaram os sintomas de toxicidade à contaminação de $\mathrm{Cu}$ : redução de crescimento e desenvolvimento anormal da gema apical.

As variáveis avaliadas (MSR, MSPA, MST, PRAIZ, PPA, TPA, CRAIZ, CPA, PCR, PCPA e DTPA) foram significativamente $(\mathrm{p}<0,01)$ afetadas pelas doses de $\mathrm{Cu}$ aplicadas, salvo o teor do metal na raiz (TRAIZ), que não foi afetado pelos tratamentos (Tabela 3). Nos modelos avaliados para descrever os dados predominou o de raiz quadrada, à exceção das variáveis TPA e CTPA, para as quais o modelo linear foi o mais adequado.

A máxima produção de matéria seca total (MST) do cedro-rosa, estimada a partir da equação de regressão (Tabela 3), foi obtida na dose de 101,74 $\mathrm{mg} \mathrm{kg}^{-1}$, sugerindo 
Tabela 3 - Equações de regressão das variáveis da raiz e parte aérea de mudas de cedro-rosa em resposta aos tratamentos com doses crescentes de $\mathrm{Cu}$.

Table 3 - Regression equations for variables of root and aerial part of Cedrela fissilis in function of treatments with increasing $\mathrm{Cu}$ doses.

\begin{tabular}{|c|c|c|}
\hline Variáveis & Equação de regressão & $\mathrm{R}^{2}$ \\
\hline MSR & $\hat{Y}=11,0+1,9518 * *{ }^{*} \mathrm{x}-0,08677^{* *} \mathrm{x}$ & 0,43 \\
\hline MSPA & $\hat{Y}=8,10+0,233^{*}{ }^{\prime} x-0,01781^{*} x$ & 0,43 \\
\hline MST & $\hat{Y}=19,1+2,1848 * * " x-0,1046 * * x$ & 0,40 \\
\hline PRAIZ & $\hat{Y}=57,4+1,8728 *{ }^{*} x-0,058 *^{*} x$ & 0,90 \\
\hline PPA & $\hat{Y}=42,6-1,8728 * ” x+0,058 * x$ & 0,90 \\
\hline TPA & $\hat{Y}=4,07+0,2561 * * X$ & 0,97 \\
\hline CRAIZ & $\hat{Y}=-0,0385+0,6913 * *{ }^{*} x+0,0031 * * x$ & 0,86 \\
\hline СТPA & $\hat{Y}=0,0360+0,00106 * x$ & 0,95 \\
\hline СТP & $\hat{Y}=0,0411+0,6808 * *{ }^{\prime} \mathrm{X}+0,004595 * * \mathrm{X}$ & 0,87 \\
\hline PCR & $\hat{Y}=61,7+5,7122 * * ” x-0,1866 * * x$ & 0,99 \\
\hline PCPA & $\hat{Y}=38,3-5,71 * * \cdots x+0,1866 * * x$ & 0,99 \\
\hline
\end{tabular}

** e $*$ : significativos, respectivamente, a $1 \%$ e a $5 \%$ de probabilidade, pelo teste F. Matéria seca da raiz (MSR) e da parte aérea (MSPA) e matéria seca total (MST). Partição de matéria seca entre raiz (PRAIZ) e parte aérea (PPA). Teor de Cu na parte aérea (TPA). Conteúdo de Cu na raiz (CRAIZ) e na parte aérea (CPA). Partição do conteúdo de Cu entre raiz (PCR) e parte aérea (PCPA).

a tolerância dessa espécie ao Cu superior ao valor de alerta (CETESB, 2001) e de precaução (CONAMA, 2009). Da mesma forma, a máxima produção estimada na parte aérea (MSPA) foi verificada na dose de 233,94 $\mathrm{mg} \mathrm{kg}^{-1}$ e, na raiz (MSR), na dose de 74,63 $\mathrm{mg} \mathrm{kg}^{-1}$. Esses dados, em princípio, sugerem que a parte aérea do cedro-rosa seja mais tolerante à concentração de $\mathrm{Cu}$ do que o sistema radicular. No entanto, a elevada concentração de Cu na parte aérea pode ter ligação com o fator de diluição ocorrido pela partição de matéria seca entre raiz (PRAIZ) e parte aérea (PPA). Houve maior alocação de fotoassimilados na raiz em detrimento da parte aérea. O ponto de máxima derivada da equação de regressão foi verificado na dose de $500 \mathrm{mg} \mathrm{kg}^{-1}$, com 70\% dos fotoassimilados direcionados à raiz (Tabela 3 ).

Os teores de Cu na parte aérea (TPA) tiveram relação linear e positiva com as doses de Cu aplicadas ao solo (Tabela 3), entretanto, como já indicado, os teores obtidos na raiz (TRAIZ) não responderam aos tratamentos.

Os conteúdos de Cu total (CPT) na raiz (CRAIZ) e na parte aérea (CTPA) responderam, entretanto, positivamente às doses aplicadas $(\mathrm{p}<0,01)$. A comparação entre os conteúdos obtidos na raiz e na parte aérea indica que CRAIZ foi superior ao CTPA, revelando a importância do sistema radicular como local de acúmulo de $\mathrm{Cu}$. Os resultados de partição do conteúdo de $\mathrm{Cu}$ (PCR e PCPA) corroboram aqueles previamente apresentados, sugerindo o acúmulo preferencial de $\mathrm{Cu}$ na raiz, em detrimento da sua translocação para a parte aérea.

\section{DISCUSSÃO}

Os sintomas de toxicidade demonstrados pelas mudas são citados na literatura científica. De acordo com Kabata-Pendias e Pendias (2001), a clorose e malformação de raízes são as características mais comuns induzidas pela toxicidade de $\mathrm{Cu}$ nas plantas. Esses mesmos autores citaram que o excesso de Cu também causa decréscimo na eficiência fotossintética, por interferir na cadeia transportadora de elétrons do fotossistema I, ocasionando a depressão de crescimento de plantas sensíveis.

A maior produção de MSR obtida é, entretanto, um fato interessante a ser destacado. Arduini et al. (1996), trabalhando com as arbóreas Pinus pinea (L.), Pinus pinaster (Ait.) e Fraxinus angustifolia (Vahl.), crescidas em solução nutritiva com diferentes concentrações de $\mathrm{CuSO}_{4}(0,012-5 \mathrm{mM})$ e $\mathrm{CdSO}_{4}(0,0$ - $5 \mathrm{mM}$ ), verificaram que tais espécies acumularam mais Cu do que Cd e que as duas espécies de pinus apresentaram maior desenvolvimento da raiz em relação às espécies sensíveis. Os autores atribuíram tal fato a um mecanismo de proteção dessas plantas contra a absorção de metais pesados. Nas microanálises conduzidas em seções de raízes de F. angustifolia, foi observado que o $\mathrm{Cu}$ ficou imobilizado predominantemente na parede celular em vez do córtex. Essa observação sugere uma característica de resistência à contaminação com $\mathrm{Cu}$. Visando ao uso em práticas de fitorremediação, o maior desenvolvimento do sistema radicular é desejável, visto que, além de permitir a colonização mais efetiva do ambiente contaminado, contribui, por meio da CTC radicular, para a maior adsorção dos metais pesados na parede celular das raízes, diminuindo a atividade iônica do contaminante na solução do solo e promovendo um ambiente de menor estresse para a planta.

Embora não se tenha verificado efeito do incremento das doses aplicadas de Cu sobre os teores do elemento na raiz (TRAIZ), os dados obtidos foram nitidamente

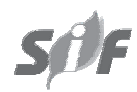

Revista Árvore, Viçosa-MG, v.35, n.6, p.1181-1188, 2011 
superiores aos da parte aérea (TPA) (Tabela 4), o que foi relacionado ao alto coeficiente de variação dos resultados. Os teores de Cu na raiz constatados neste estudo divergem daqueles obtidos por Soares et al. (2001), que estudaram a mesma espécie em um Latossolo Vermelho-Amarelo (LVA) misturado com substrato multicontaminado (relação 40\% LVA : 60\% SMC) com metais pesados, entre eles o Cu na concentração de $1.000 \mathrm{mg} \mathrm{kg}^{-1}$. Os teores encontrados pelos referidos autores nas raízes foram bem inferiores aos obtidos nesta pesquisa. Como explicações possíveis para essa diferença de resposta, podem ser considerados o uso de solo de textura média neste trabalho, portanto com menor conteúdo de argila, o que implica maior disponibilidade do contaminante, mesmo nas menores doses; o próprio tempo de cultivo diferenciado nos dois estudos; e a presença de outros contaminantes no estudo citado.

Como indicado, a maior acumulação de um contaminante na raiz é interessante em estudos de fitorremediação. Dessa forma, os dados sugerem que o cedro-rosa possui potencial promissor para ser usado nesse tipo de técnica. Obviamente que a condução de ensaios que considerem um período maior de cultivo, inclusive chegando à fase adulta, seria muito interessante para fins mais conclusivos.

Esse potencial das mudas de cedro-rosa é confirmado na análise do fator de bioconcentração (FBC) (Tabela 4), que indica claramente que a espécie

Tabela 4 - Teores de cobre no solo, na raiz (TRAIZ) e na parte aérea (TPA) e fator de bioconcentração (FBC) da raiz (RA) e parte aérea (PA) do cedrorosa em resposta aos tratamentos com doses crescentes de $\mathrm{Cu}$.

Table 4 - Copper levels in soil, root (TRAIZ), aerial part (TPA) and bioconcentration factor (BCF) of Cedrela fissilis root $(R A)$ and aerial part $(P A)$ in function of treatments with increasing $\mathrm{Cu}$ doses.

\begin{tabular}{cccccc}
\hline DOSE & $\begin{array}{c}\text { TEOR } \\
\text { NO SOLO* }\end{array}$ & TRAIZ & TPA & FBC-RA & FBC-PA \\
\cline { 2 - 4 } $\mathrm{mg} \mathrm{kg}^{-1}$ & \multicolumn{5}{c}{$\mathrm{mg} \mathrm{kg}^{-1}$} \\
\cline { 2 - 4 } & 0,17 & 12,0 & 21,1 & 70,6 & 124,1 \\
60 & 28,4 & 155,1 & 30,0 & 5,46 & 1,05 \\
80 & 41,5 & 314,7 & 34,7 & 7,58 & 0,83 \\
100 & 65,8 & 348,7 & 28,6 & 5,29 & 0,43 \\
500 & 114,8 & $1.572,1$ & 129,0 & 13,69 & 1,12 \\
\hline
\end{tabular}

(*) Teores considerados disponíveis com extrator DTPA a pH 7,30 (ABREU et al., 2001). florestal avaliada apresenta característica acumuladora de Cu na raiz (FBC-RA). Já na parte aérea o FBC-PA indicou tendência oposta, ou seja, uma tendência exclusora de $\mathrm{Cu}$ nesse compartimento do vegetal.

A indicação de tolerância do cedro-rosa aos efeitos do Cu também foi verificada por Marques et al. (2000). Entretanto, os resultados aqui obtidos em um solo não argiloso fortalecem ainda mais o potencial da espécie florestal estudada como fitorremediadora, uma vez que tais solos são reconhecidamente de baixo poder adsortivo, ou seja, nos quais os elementos químicos estão mais disponíveis para a absorção pelos tecidos vegetais.

A aplicação prática da tolerância verificada das mudas de cedro-rosa ao solo contaminado por Cu é a recomendação dessa espécie arbórea nos estágios iniciais dos processos de fitorremediação, focando-se em especial na diminuição da contaminação, na cobertura vegetal da área e na diminuição da dispersão dos contaminantes. Em trabalhos de recuperação de áreas degradadas, tal potencial é associado à fitoestabilização do solo, evitando a dispersão do contaminante por lixiviação e erosão e acumulando-o na raiz. A expectativa para a árvore adulta é promissora para fins da fitoextração de $\mathrm{Cu}$, tendo em vista que o estabelecimento e pegamento das mudas costumam ser as fases mais críticas nos processos de fitorremediação.

\section{CONCLUSÃO}

Na avaliação dos efeitos de doses de Cu sobre o desenvolvimento de mudas de cedro-rosa, em condições de estufa e na região da Zona da Mata de Minas Gerais, pode-se concluir que:

1. O aumento dos teores de $\mathrm{Cu}$ no solo promove maior crescimento das raízes das mudas de cedro-rosa em detrimento da parte aérea.

2. As mudas de cedro-rosa apresentam elevada capacidade de acúmulo de Cu nas raízes, com exclusão do metal na parte aérea.

3. As mudas de cedro-rosa possuem potencial de uso na fitorremediação de solos contaminados por $\mathrm{Cu}$.

\section{AGRADECIMENTOS}

Os autores agradecem à Capes e ao Departamento de Solos da Universidade Federal de Viçosa pela concessão da bolsa de pós-graduação. 


\section{REFERÊNCIAS}

ABREU, C. A.; ABREU, M. F.; ANDRADE, J. C. Determinação de cobre, ferro, manganês, zinco, cádmio, cromo, níquel e chumbo em solos usando a solução de DTPA em pH 7,3. In: RAIJ, B. van et al. (Eds.). Análise química para avaliação da fertilidade de solos tropicais. Campinas: Instituto Agronomico de Campinas, 2001. p.240-250.

ACCIOLY, A. M. A.; SIQUEIRA, J. O.

Contaminação química e biorremediação do solo. In: NOVAIS, R. F.; ALVAREZ V., V. H.; SCHAEFER, C. E. G. R. Tópicos de ciência do solo. Viçosa, MG: Sociedade Brasileira de Ciência do Solo, 2000. v.1. p.299-352.

ALLOWAY, B. J. Heavy metals in soils. New York: John Wiley, 1993. 339p.

ARDUINI, I.; GODBOLD, D. L.; ONNIS, A. Cadmium and copper uptake and distribution in Mediterranean tree seedlings. Physiologia Plantarum, v.97, n, 1, p.111-117, 1996.

BAKER, A. J. M. Metal tolerance. New Phytology, v.106, n.1, p.93-111, 1987.

CAIRES, S. M. et al. Tolerância de mudas de espécies arbóreas nativas em solo contaminado com metais pesados. In: CONGRESSO

BRASILEIRO DE CIÊNCIA DO SOLO - SOLOS, SUSTENTABILIDADE E QUALIDADE AMBIENTAL, 30., Recife, 2005. Resumos... Recife, 2005. CD ROOM.

CETESB. Relatório de Estabelecimento de Valores Orientadores para Solos e Águas Subterrâneas no Estado de São Paulo. São Paulo: 2001. 73p.

CONSELHO NACIONAL DO MEIO AMBIENTE CONAMA. Resolução CONAMA $\mathbf{N}^{\circ} \mathbf{4 2 0 /}$ 2009 Disponível em http://www.mma.gov.br/port/ conama/legiabre.cfm?codlegi $=620$

DENNY, H. J.; WILKINS, D. A. Zinc tolerance in Betula ssp.: I Effect of external concentration of zinc on growth and uptake. New Phytologist, v.106, n.3, p.517-524, 1987.

FISHER, R. F. Amelioration of degraded rain forest soils by plantations of native tree. Soil

Science Society America Journal, v.59, n.2, p.544-549, 1995.
KABATA-PENDIAS, A.; PENDIAS, H. Trace elements in soils and plants. 3.ed. Boca Raton, CRC Press, 2001. 315p.

KABATA-PENDIAS, A. Soil-Plant transfer of trace elements - an environmental issue. Geoderma, v.122, n.2/4, p.143-149, 2004.

LARCHER, W. Ecofisiologia vegetal. São Carlos: Rima, 2004. 531p.

LOMBI, E., et al. Phytoremediation of heavy metal-contaminated soils: natural hyperaccumulation versus chemically enhanced phytoextraction. Journal Environmental Quality, v.30, p.1919-1926, 2001.

MARQUES, T. C. L. L. S. M.; MOREIRA, F. M. S.; SIQUEIRA, J. O. Crescimento e teor de metais de mudas de espécies arbóreas cultivadas em solo contaminado com metais pesados.

Pesquisa Agropecuária Brasileira, v.35, n.1, p.121-132, 2000.

MELO, R. F. et al. Potencial de quatro espécies herbáceas forrageiras para fitorremediação de solo contaminado por arsênio. Revista Brasileira de Ciência do Solo, v.33, n.2, p.455-465, 2009.

PAIVA, H. N.; CARVALHO, J. G.; SIQUEIRA, J. O. Teor de nutrientes em mudas de Cedro (Cedrela fissilis Vell.) submetidas a doses crescentes de níquel, em solução nutritiva. Revista Árvore, v.26, n.3, p.279-284, 2002a.

PAIVA, H. N.; CARVALHO, J. G.; SIQUEIRA, J. O. Índice de translocação de nutrientes em mudas de Cedro (Cedrela fissilis Vell.) e Ipê-Roxo (Tabebuia impetiginosa (Mart.) Standl.) submetidas a doses crescentes de cádmio, níquel e chumbo. Revista Árvore, v.26, n.4, p.467-473, 2002 b.

PAIVA, H. N. et al. Influência de doses crescentes de chumbo sobre o teor e o conteúdo de nutrientes e $\mathrm{Pb}$ em mudas de Ipê-Roxo (Tabebuia impetiginosa (Mart.) Standl.). Revista Árvore, v.27, n.1, p.151-158, 2003.

PULFORD, I. D.; WATSON, C. Phytoremediation of heavy metal-contaminated land bay trees - a review. Environment International, v.29, n.4, p.529-540, 2003.

RIBEIRO JÚNIOR, J. I. Análises estatísticas no SAEG. Viçosa, MG: Universidade Federal de Viçosa, 2001. 301p.

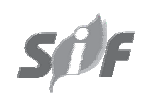

Revista Árvore, Viçosa-MG, v.35, n.6, p.1181-1188, 2011 
ROSSELLI, W.; KELLER, C.; BOSCHI, K.

Phytoextraction capacity of trees growing on a metal contaminated soil. Plant and Soil, v.256, n.1, p.265-272, 2003.

RUIZ, H. A.; FERREIRA, G. B.; PEREIRA, J. B. Estimativa da capacidade de campo de Latossolos e Neossolos Quartzarênicos pela determinação do equivalente de umidade. Revista Brasileira de Ciência do Solo, v.27, n.2, p.389-393, 2003.

SAKURAGUI, C. M.; STEFANO, M. V.; CALAZANS, L. S. B. Meliaceae. In: Lista de Espécies da Flora do Brasil. Jardim Botânico do Rio de Janeiro. Disponível em: <http://floradobrasil.jbrj.gov.br/2010/FB009990>. Acesso em: 07 de out. 2010.

SALT, D. E.; SMITH, R. D.; RASKIN, I. Phytoremediation. Annual Review Plant Physiology Plant Biology, v.49, p.643-668, 1998.

SOARES, C. R. F. S. et al. Acúmulo e distribuição de metais pesados nas raízes, caule e folhas de mudas de árvores em solo contaminado por rejeitos de indústria de zinco. Revista Brasileira de Fisiologia Vegetal. v.13, n.3, p.302-315, 2001.
STORCK, L. et al. Experimentação vegetal. Santa Maria: Universidade Federal de Santa Maria, 2001.

TURNER, R.G. Heavy metal tolerance in plants. In: RORISON, I. H. (Ed.) Ecological aspects of the mineral nutrition of plants. Oxford: Blackwell Scientific Publications, 1969.p.399-410,

VANGRONSVELD, J. et al. Rehabilitation studies on an old non-ferrous waste dumping ground: effects of revegetation and metal immobilisation by beringite. Journal Geochemistry Explorer v.52, n.1, p.221-229, 1995.

VERVAEKE, P. et al. Phytoremediation prospects of willow stands on contaminated sediment: a field trial. Environmental Pollution, v.126, n.1, p.275-282, 2003.

WOOLHOUSE, H. W. Toxicity and tolerance in the responses of plants to metals. In: LANGE, O. L. et al. (Eds.). Encyclopedia of plant physiology. 3.ed. Berlin: Springer, 1983. v.12. p.245-289. 